American Journal of Pharmaceutical Education 2017; 81 (1) Article 6.

\title{
RESEARCH
}

\section{Methods Used by Colleges and Schools of Pharmacy to Prepare Student Pharmacists for Careers in Academia}

\author{
Seena L. Haines, PharmD, ${ }^{a}$ Eliza A. Dy-Boarman, PharmD, ${ }^{b}$ Kalin M. Clifford, PharmD, ${ }^{c}$ \\ Maria A. Summa, PharmD, ${ }^{d}$ Megan N. Willson, PharmD, ${ }^{\text {e Jaclyn A. Boyle, PharmD, MS, }}{ }^{f}$ \\ Michael J. Peeters, PharmD, MEd. ${ }^{\mathrm{g}}$ \\ ${ }^{a}$ University of Mississippi, Jackson, Mississippi \\ ${ }^{\mathrm{b}}$ Drake University, Des Moines, Iowa \\ ${ }^{c}$ Texas Tech University Health Sciences Center, Dallas, Texas \\ ${ }^{\mathrm{d}}$ University of Saint Joseph, Hartford, Connecticut \\ ${ }^{\mathrm{e}}$ Washington State University, Spokane, Washington \\ ${ }^{\mathrm{f}}$ Northeast Ohio Medical University, Rootstown, Ohio \\ ${ }^{\mathrm{g}}$ University of Toledo, Toledo, Ohio
}

Submitted September 11, 2015; accepted November 10, 2015; published February 25, 2017.

Objective. To identify the methods used by US colleges and schools of pharmacy to prepare student pharmacists for academic careers.

Method. An 18-item survey instrument was developed and distributed to US colleges and schools of pharmacy. Representatives were asked about faculty responsibilities, experiences in academia currently offered to student pharmacists, and representatives' perception of their student pharmacists' preparedness for careers in academia, including barriers in current programming.

Results. Representatives from 96 colleges/schools responded. The vast majority (96\%) provided academia-focused advanced pharmacy practice experiences (APPEs), 40\% provided didactic coursework in academia, $28 \%$ offered a longitudinal research track, and $42 \%$ offered academia-focused independent studies. Teaching methods and creating learning objectives were the most common pedagogical content, while assessment activities were diverse. Time was the most prevalent barrier to providing training for academic careers; however, degree of student pharmacist interest, faculty inexperience, and lack of leadership support were also commonly reported.

Conclusions: Colleges and schools of pharmacy vary in the extent to which they prepare student pharmacists for careers in academia. Advanced pharmacy practice experiences were the most common method of training offered. Standardization of training for academia may better promote this career path to student pharmacists.

Keywords: student preparation, career, academia, training

\section{INTRODUCTION}

Faculty recruitment and retention continues to be a top issue and opportunity for growth among colleges and schools of pharmacy. As of September 2015, there were 132 US colleges and schools of pharmacy with accredited (full or candidate status) professional degree programs and three with precandidate status, compared to 80 schools 15 years ago, representing a $60 \%$ increase since the year 2000. ${ }^{1}$ In addition to the increased demand

Corresponding Author: Seena L. Haines, 2500 North State St., Jackson, MS 39216. Tel: 601-815-0856. Fax: 601-984-2618. E-mail: shaines@umc.edu

(Note: At time of submission, Seena L. Haines was affiliated with Palm Beach Atlantic University) for pharmacy faculty members created by this increase in the number of colleges and schools of pharmacy, other challenges in attracting qualified pharmacists to careers within academic pharmacy include salary differences, a lack of formalized training and experience in the grant writing process, and concerns about faculty members having to fund a portion of their salary through research grants or clinical practice. ${ }^{2}$ Despite the ever-increasing need for pharmacy faculty members, largely in the pharmacy practice domain, career development programs for those interested in pursuing academic paths only recently have become more prominent. Factors that influence the career goals of student pharmacists have been described and have largely pointed to career paths in community and institutional practice settings. 3,4 


\section{American Journal of Pharmaceutical Education 2017; 81 (1) Article 6.}

Beyond being a learner, student pharmacists' formal exposure to teaching during pharmacy education is largely voluntary. Some schools of pharmacy have published their experiences with exposing student pharmacists to an academic career through an elective course. ${ }^{5,6}$ Others have reported their impact from providing academic advanced pharmacy practice experiences (APPEs). ${ }^{7-11}$ The three main pillars associated with the life of an academician (teaching, scholarship, and service) are not often a focal area for pharmacy practice residencies, unless offered as an area of emphasis embedded within specialty training or possibly described in a resident teaching and learning curriculum. Success in academia is often attributed to a solid foundation in all three aforementioned pillars. Toward this goal, many colleges and schools of pharmacy offer a structured professional development program for new faculty members to assist in transitioning into academia to enhance pedagogical prowess, productive scholarship, and helpful service. ${ }^{12-17}$ Established programs may also provide formal mentoring, academic resources, and individual professional development needs.

More recently, the American Association of Colleges of Pharmacy (AACP) has promoted several grants, fellowships, and scholarship programs to encourage student pharmacists to enhance their preparation for a career in academic pharmacy. ${ }^{18}$ Improving the early exposure of student pharmacists to academic career paths could have a favorable impact on the number who explore, elect, and subsequently remain in educator roles. In 2013, AACP set out to develop a model curriculum for training student pharmacists interested in academic pharmacy and to distribute that model, along with information about the academy and academic careers, to all schools and colleges of pharmacy. The Student Engagement Task Force (SETF) was tasked with accomplishing this. During an initial evaluation in which task force members compared their own colleges and schools of pharmacy, a lot of variability was found within academic APPE curricula. No standard of expectations existed for teaching experiences offered by schools and colleges of pharmacy, although the pharmacy literature contained many examples of organized academic preparation programs for pharmacy residents and fellows. ${ }^{19-32}$ To accomplish this charge, the subcommittee decided that a national-level survey was needed to identify best practices and current trends.

Given the academy's charge to develop a model curriculum for training individuals for pharmacy faculty positions in the setting of several unknowns about the landscape of academic programming offered by schools and colleges of pharmacy, the task force sought to first describe the current state of academic advanced pharmacy practice experiences or academic educational tracks at schools and colleges of pharmacy within the United States. This information will be used to provide a framework for designing a model curriculum, provide standardization, and ensure similar outcomes and quality between academic institutions. In this paper, we describe pharmacy academic career planning and preparation by US colleges and schools of pharmacy.

\section{METHODS}

The Washington State University Office of Research Assurances found this project to be exempt from the need for review by the Investigational Review Board.

A subcommittee of the AACP's Pharmacy Practice Section SETF conducted a literature review to identify gaps of knowledge in the area of academic preparation experiences for student pharmacists and then incorporated into the survey items. Subsequently, members of the SETF created a pool of survey items based on their 45 years of combined academic experience in preparing student pharmacists for academia. The survey instrument was pretested by the task force chair, subcommittee members, and an outside institutional assessment specialist. Feedback regarding the clarity and format of survey questions was collected and incorporated into a revised survey instrument. The final survey materials included an introduction describing the purpose of the study, an explanation of informed consent, and the 18-item survey instrument.

This 18-item survey instrument was divided into three sections. The first section solicited information about the college or school's demographics for faculty full time equivalents, number of student pharmacists enrolled, and type of program. The second section asked selected and constructed questions concerning curriculum, structure of offerings, coordination, and assessment of the academic preparatory experience. The final section asked about the respondent's perception of student pharmacist preparedness for academic careers and gaps in the current curriculum. Respondents were asked to rate each statement on a 4-point scale ranging from strongly agree to strongly disagree.

The respondent pool for the survey was identified through the AACP faculty database. Purposive sampling was used to ensure that a representative from every institution had an opportunity to respond, while only one representative responded from each institution. The AACP provided faculty registries that represented the curriculum special interest group, department chairs of pharmacy practice, and the experiential section. The survey instrument was originally sent to members listed as department chairs at each college and school of pharmacy, experiential special interest group, and to the curriculum special interest group to represent 124 colleges or 


\section{American Journal of Pharmaceutical Education 2017; 81 (1) Article 6.}

schools of pharmacy at the time of survey implementation. Inclusion criteria were all department chairs, experiential directors, and other faculty designees who could report on academic career preparation of student pharmacists. Exclusion criteria were nonaccredited colleges or schools of pharmacy and colleges or schools of pharmacy located outside of the United States.

The survey was launched and data were collated using the survey tool Qualtrics (www.qualtrics.com). The study was conducted from February 11, 2015, through June 4, 2015. To enhance our response rate, we sent reminder emails to those who had not responded to the original survey invitation. For any college or school that submitted more than one survey response, an email was sent to the respondents to identify which response set was most reflective of that institution. In cases where we were not successful in re-contacting the multiple respondents, the senior/administrative person's responses were used. If needed, pharmacy practice chairs from participant institutions were asked to coordinate a collaborative response in order to remove the duplications that were received.

The data were exported to Microsoft Excel. Data were analyzed with SPSS, version 19 for Mac (IBM; Armonk, NY); the majority of data were summarized with frequencies. The reported results reflect most of the survey item responses, except for a series of questions that asked respondents' opinions regarding their institution's preparation of student pharmacists for a variety of aspects of academic careers. These questions were combined into a Likert scale's total score, ${ }^{33}$ and its internal consistency analyzed using a Cronbach's alpha. ${ }^{34}$ As appropriate for Likert scales, ${ }^{33}$ only the total scores (considered to be continuous data ${ }^{33}$ ) were used for later inferential statistical analysis. Planned a priori, this opinion scale's total scores were analyzed with two separate ANOVAs; one for scores based on the number of student pharmacists at their institution, and the other for scores based on the format and length of academic-focused advanced pharmacy practice experiences.

\section{RESULTS}

A representative from 96 of 124 colleges and schools of pharmacy responded to this survey ( $77 \%$ response rate). The majority (57\%) of programs were $2+4$ programs, while $26 \%$ required students to earn a bachelor's degree prior to admission. Most (98\%) programs had more than 50 student pharmacists in each class, while half $(52 \%)$ had more than 100 student pharmacists, and a quarter (22\%) had more than 150 student pharmacists per class.

Most ( $72 \%)$ of the programs reported that faculty members were involved in preparing student pharmacists for academic careers. In response to the question regarding prerequisites, most (76\%) programs did not require prerequisites for student pharmacists desiring to be involved in academic pharmacy experiences; however, a minority of programs did. Common prerequisites among those 15 respondents was prior academic performance of each interested student pharmacist reported by seven (47\%) colleges and schools, while six (40\%) programs request a reflection statement regarding the student pharmacist's potential interest in academia, four $(27 \%)$ programs require prerequisite coursework, and two $(13 \%)$ programs require a letter of recommendation. Many PharmD programs provide multiple experiences for student pharmacists to gain exposure to academia. The most common methods were academic APPEs (96\%) and independent study courses (42\%). Less common methods of exposure to academia were required didactic courses $(2 \%)$ and a structured longitudinal experiential track (4\%). Table 1 describes other methods used by PharmD programs to expose student pharmacists to academic careers in pharmacy.

Another question was asked regarding length of APPEs used for delivering academic experiences. Most programs (95\%) used a standard block rotation of 4 to 6 weeks for student pharmacists to complete an academiafocused APPE, while some (5\%) other programs used a longitudinal experience covering either one or two academic terms (Figure 1). Most (68\%) of these were taught by one faculty member, while about one-third (32\%) used multiple faculty members to deliver portions of an academia-focused experience to student pharmacists. Many programs responded that they promoted and taught various aspects of academic pharmacy. Most experiences included content regarding teaching methods $(49 \%)$ and developing learning objectives (45\%), while some experiences included discussion on educational theory $(67 \%)$ and awareness of scholarship types (58\%). However almost half $(46 \%)$ of programs did not provide grant-writing activities during any of their academic experiences. Other content areas are reported in Table 2. Common assessment activities from PharmD programs from academic APPE experiences include attending lectures/activities provided by faculty members $(66 \%)$ and developing lesson plans (63\%). Other less common assessment activities are preparation of grant proposals (6\%) and delivering continuing education programs for other health care professionals (6\%). Table 3 also describes other activities that are being assessed during academic-related experiences.

The scale was designed to assess the respondents' opinions regarding preparedness for a student pharmacist to begin a career in academia. The seven-item questions used a four-point Likert response format, and are reported in Table 4 . When the seven items were summed into 


\section{American Journal of Pharmaceutical Education 2017; 81 (1) Article 6.}

Table 1. Program Methods for Student Pharmacist Exposure to Academic Careers in Pharmacy

\begin{tabular}{lc}
\hline Method of Exposure & Programs That Use This Method (\%) \\
\hline Advanced pharmacy practice experience & 96 \\
Structured short-term research experience & 44 \\
Pharmacy organization (eg, AACP) & 44 \\
Independent study & 42 \\
Lecture(s) within elective course & 40 \\
Lecture(s) within required course & 39 \\
Elective didactic course & 27 \\
Structured longitudinal research track & 23 \\
Introductory pharmacy practice experience & 14 \\
Structured longitudinal curricular track & 8 \\
Other & \\
Structured longitudinal experiential track & 5 \\
Required didactic course & 4 \\
\hline
\end{tabular}

Abbreviations: AACP $=$ American Association of Colleges of Pharmacy

${ }^{a}$ Career Day, Rotation Fair, Academia Mentoring Program, student involvement on faculty committees

a Likert scale, it had an internal consistency of .83. Most respondents strongly agreed that student pharmacists were prepared to pursue a residency or fellowship regardless of whether the postgraduate training has an academic appointment (median $=4, \mathrm{IQR}=1$ ). Respondents also disagreed most often that student pharmacists understood the components of service or scholarship (both median $=2$, $\mathrm{IQR}=1)$. The other items saw agreement among many respondents regarding student pharmacist preparedness to educate health care professionals and patients, as well as student pharmacists having a good understanding of teaching (all median $=3, \mathrm{IQR}=1$ ).

Respondents' opinions of their program's preparation of student pharmacists for academia did not have significant associations with either the number of student pharmacists in each year's class at their institution or the format and length of academic-focused APPEs $(p=.3$, $p=.79$ respectively).

According to respondents, a number of challenges exist in delivering the current programming intended to help student pharmacists explore academia as a career

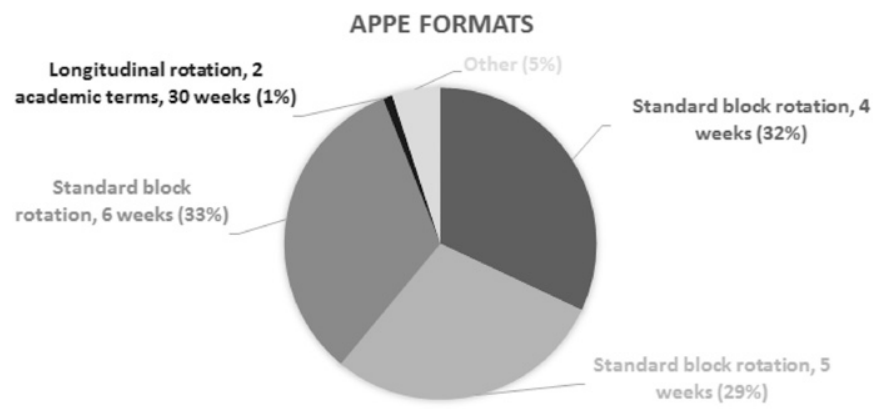

Figure 1. Format of Academia-focused Advanced Pharmacy Practice Experiences opportunity (Figure 2). Time was the most prevalent barrier, while student pharmacist interest, faculty inexperience, and leadership support were also commonly reported.

\section{DISCUSSION}

Our results highlight some similarities among US pharmacy education programs; however, there are several differences in the specific ways that programs expose student pharmacists to academic pharmacy. While three-quarters of programs provided some type of student pharmacist preparation for an academic career, this study also highlights the continued opportunity for growth in this area. A career in academia could be an appealing opportunity for graduates who thrive in a diverse and dynamic work environment engaging a diverse group of learners (student pharmacists, residents, postgraduate fellows, patients, and providers). Student pharmacists should experience these; to expect graduates to pursue a career in academia without prior experiences seems unacceptable. An academician may serve as a clinicianeducator or researcher-educator. Beyond a college or school of pharmacy, many academicians can have academic appointments in medical, veterinary, and other allied healthrelated fields. Academic duties are multi-faceted (service, scholarship, and teaching). These duties often include administrative activities, scientific research, instruction in the classroom (synchronous and asynchronous) and experiential settings, supervising student pharmacists, residents, graduate students, organization and service engagement, and academic and professional advising. Student pharmacists may not be aware of faculty members' involvement in research, school-related service, or clinical responsibilities, in addition to the time they spend in 


\section{American Journal of Pharmaceutical Education 2017; 81 (1) Article 6.}

Table 2. Curriculum Content That Provides Pharmacy Academia Experience (Coursework, Academia Track, Experiential Rotation) at 76 US Schools and Colleges of Pharmacy

\begin{tabular}{lccc}
\hline & $\begin{array}{c}\text { No Academic } \\
\text { IPPE/APPE Includes } \\
\text { This (\%) }\end{array}$ & $\begin{array}{c}\text { Few Academic } \\
\text { IPPE/APPE Include } \\
\text { This (\%) }\end{array}$ & $\begin{array}{c}\text { Most Academic } \\
\text { IPPE/APPE Include } \\
\text { This (\%) }\end{array}$ \\
\hline Educational theory & 12 & 67 & 21 \\
Developing syllabi/courses & 14 & 57 & 29 \\
Developing learning objectives & 4 & 51 & 45 \\
Outcomes-based planning & 13 & 60 & 27 \\
Teaching Methods & 3 & 48 & 49 \\
Instructional Technology & 7 & 54 & 39 \\
Assessment Strategies & 7 & 54 & 38 \\
Test-question writing strategies & 9 & 49 & 42 \\
Awareness of scholarship types & 8 & 63 & 29 \\
Awareness of service types & 7 & 58 & 35 \\
Grant writing and resources & 46 & 50 & 4 \\
Advising and mentoring & 24 & 47 & 29 \\
Faculty peer evaluation & 33 & 48 & 19 \\
Promotion and tenure process & 34 & 44 & 22 \\
Accreditation readiness & 27 & 56 & 17 \\
Developing a teaching portfolio & 25 & 55 & 20 \\
Higher education policies and procedures & 27 & 57 & 16 \\
Other ${ }^{2}$ & 7 & 4 & 3 \\
\hline Abbrition
\end{tabular}

Abbreviations: APPE=Advanced Pharmacy Practice Experience; IPPE = Introductory Pharmacy Practice Experience

${ }^{a}$ Nothing further was specified

the classroom, nor may they be fully aware of the faculty member's roles in the design, development, implementation, and assessment of teaching and learning.

This research demonstrates that the most common method used at US colleges and schools of pharmacy to expose student pharmacists to academic pharmacy, is a short-term (four, five, or six-week) elective APPE. This potential demand on pharmacy practice faculty workload is important to note as programs seek to expand opportunities for academic APPEs. Furthermore, significant opportunity exists to expand APPE offerings to faculty members within other departments and administration to allow student pharmacists to gain an understanding of various faculty roles in teaching, scholarship, and service. We also illustrated that there is substantial variety in the content and assessment of academic APPEs. Similar to resident teaching-learning curricula, ${ }^{35}$ programs should encourage academic APPE preceptors to focus on a limited number of core concepts during these limited experiences. Finally, programs should consider the unique activities and learning assessment mechanisms for academic APPEs. The most common learning assessment mechanisms included teaching responsibilities, participation in academic meetings, and some exposure to scholarship with a preceptor (Table 3).

While not well-represented within this study's results, the following three areas are other potential academia-related learning experiences that may be considered by schools and colleges of pharmacy.

This research shows that there is opportunity at many programs across the nation for development of academic electives, given that almost half of the programs surveyed only exposed student pharmacists to academic pharmacy through a lecture in an elective course and only one-quarter offered a specific elective course in academic pharmacy. Elective courses may be able to include a more in-depth description of the academic pharmacy career path.

Curricular and experiential tracks have been used by schools of pharmacy to prepare student pharmacists for specialized or advanced areas of practice, such as research, residency and fellowship, or specific disease state management. ${ }^{36-39}$ Despite the potential advantages, the results of this study showed that only a small percentage of programs offer any type of longitudinal track focused in academic pharmacy. Because of the opportunity to cover concepts over a greater time span, longitudinal academic tracks may allow student pharmacists to complete long-term projects/assignments related to teaching, scholarship, and/or service.

This study also identified that few colleges require prerequisites from student pharmacists prior to participation in an academic APPE or academic track. Some institutions may be able to strengthen current opportunities by better 


\section{American Journal of Pharmaceutical Education 2017; 81 (1) Article 6.}

Table 3. Student Learning Assessment Mechanisms for Academic-related Experiences at 96 US Schools and Colleges of Pharmacy

\begin{tabular}{|c|c|c|}
\hline Activity for Assessment & $\begin{array}{c}\text { Programs That } \\
\text { Offer This Activity } \\
(\%)\end{array}$ & Hours, Median (IQR) \\
\hline Attend lectures/activities provided by faculty member(s) & 66 & \\
\hline Attend/participate in academic meetings & 65 & \\
\hline Develop lesson plans/course activities & 63 & \\
\hline Attend/participate in educational seminars & 59 & \\
\hline Facilitate small-group discussion/recitation & 59 & \\
\hline Deliver classroom-based lecture & 54 & $2.0(2.0)$ \\
\hline Participate in scholarship under preceptor & 53 & \\
\hline Evaluate learning activities & 52 & \\
\hline Lead classroom-based learning activity & 51 & $3.0(2.0)$ \\
\hline Write reflective statements on educational experiences & 49 & \\
\hline Design learning assessment questions (item analysis) & 45 & \\
\hline Prepare IRB proposal/application & 27 & \\
\hline Develop teaching philosophy & 25 & \\
\hline Develop syllabus (classroom, lab, or experiential) & 23 & \\
\hline Develop teaching portfolio & 19 & \\
\hline Precept IPPE students/pharmacy interns under preceptor & 15 & \\
\hline Deliver clinical site (experiential)-based lecture & 15 & $2.0(3.8)$ \\
\hline Lead clinical site (experiential)-based learning activity & 12 & $2.0(2.3)$ \\
\hline Other ${ }^{\mathrm{a}}$ & 7 & \\
\hline Deliver continuing education program for health professionals & 6 & $1.0(0.0)$ \\
\hline Prepare grant proposal/application & 6 & \\
\hline
\end{tabular}

Abbreviations: IQR = interquartile range

${ }^{a}$ Facilitate entire laboratory series, lead clinical practice laboratory activities, training on test proctoring, unknown

identification of student pharmacists with a keen interest in academia and placement of these students into academic experiences.

Faculty members agreed that student pharmacists are prepared for postgraduate training and to educate both health care providers and patients upon graduation (Table 4). However, there may be opportunities to further expose student pharmacists to an academic career path and the necessary components (teaching, service, and scholarship). The lack of statistically significant correlation of respondent's perception of their institution's academic preparation, with number of student pharmacists at an institution or format/length of APPE(s) could suggest that these factors do not appear to be influencing trends in

Table 4. Opinion Likert Scale Items for Each Institution's Preparation of Student Pharmacists for a Career in Academia $(n=80)$

Item

Students from our institution are well-informed of the option of academia as a career path

Students from our institution have a good understanding of the teaching component of academia

Students from our institution have a good understanding of the service component of academia

Students from our institution have a good understanding of the scholarship component of academia

Students from our institution are well-prepared to pursue a residency or fellowship with or without an academic appointment

Students from our institution are prepared to educate other health professionals and patients

Students from our institution are made aware of the variety of academic career choices available

Total score (out of 28, summed for all equally weighted items)
Median (Interquartile Range) ${ }^{\mathbf{a}}$ $3(2-3)$

$19.5(16-22)$

${ }^{a}$ Rating Scale: $1=$ strongly disagree; $2=$ disagree; $3=$ agree; $4=$ strongly agree 


\section{American Journal of Pharmaceutical Education 2017; 81 (1) Article 6.}

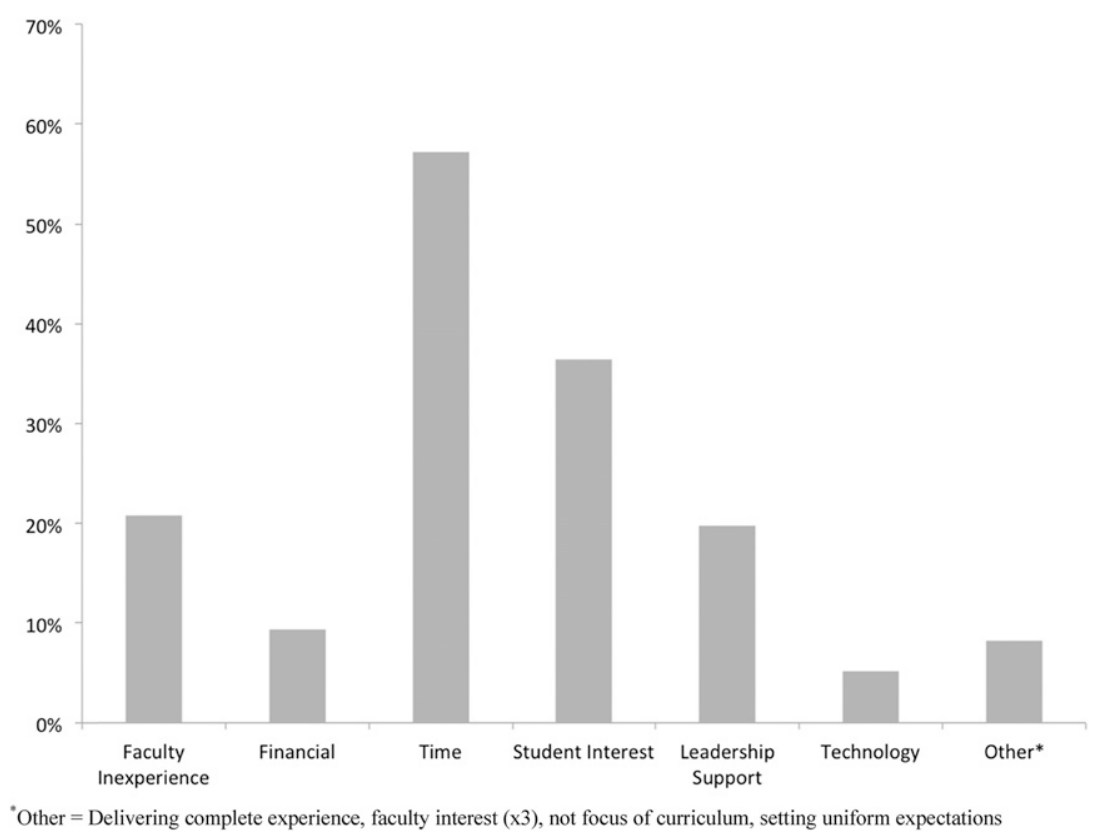

Figure 2. College/school Representatives' Perceived Institutional Gaps in Facilitating Students' Exposure to Careers in Academia

student pharmacist exposure to academic careers. Time was the most prevalent barrier to offering student pharmacists learning experiences in academic pharmacy careers (Figure 2). While PharmD curricula are tight and there are many competitors for student-contact time, we greatly encourage that faculty members continue investing their time and effort to provide students with teaching experiences in which students are placed in the educator role as opposed to their usual role as learners. Student pharmacist interest and faculty inexperience were also commonly reported as barriers. Developing a standardized curriculum can help provide students with core academic experiences and help guide inexperienced faculty to discover needed resources that may be beyond their own expertise.

One limitation of this data includes a lack of separation of academic IPPEs and APPEs in regards to nature of topics addressed. Survey respondents, depending on the depth and breadth of their responsibilities at their institutions, may have varying levels of knowledge about how student pharmacists understand all of the responsibilities associated with academic careers, which may limit our survey results.

Additionally, faculty experience and knowledge of the academic environment may have presented bias in information related to student pharmacists' understanding of responsibilities associated with academic careers. No information was gathered related to the perceived preparation of student pharmacists for academic careers. A further limitation is bias with sampling. While we used a purposive sampling framework, we only obtained responses from over three-quarters of institutions. We may have missed an aspect of student pharmacist preparation for academia, but from the wide participation among many colleges and schools of pharmacy, we are confident in generalizability of these findings.

Finally, we contacted the institutions from which we received duplicate responses and asked their respondents to coordinate and provide a collaborative response so that each institution would have only one response that was analyzed with all other responses. In retrospect, this may not have been the best method of handling duplicate responses.

Despite a decrease in faculty vacancies in recent years, there will always be a need for highly qualified pharmacy faculty members. The most recently available AACP survey of vacant budgeted and lost faculty positions found that despite a $9.3 \%$ reduction in vacancies for the 2013-2014 academic year, over $25 \%$ of available faculty positions went unfilled because qualified candidates were not available. ${ }^{40}$ Additionally, AACP's strategic plan states that increasing member engagement via programs that "enhance human resource recruitment, retention, and development" is one priority of the academy. ${ }^{41}$

One strategy to improve the preparation of student pharmacists for candidacy for future academic positions is to more deliberately promote academic pharmacy as a career within pharmacy curricula. Improving awareness of the wide scope of dynamic demands placed on pharmacy educators may help us identify those student pharmacists who are truly destined for an academic career. 


\section{American Journal of Pharmaceutical Education 2017; 81 (1) Article 6.}

Earlier exposure may improve the recruitment of student pharmacists in academic-focused postgraduate programs. Such training may ultimately improve the suitability of these program graduates for pharmacy faculty positions, as well as their sustainability in the academy. Therefore, it is imperative that colleges and schools of pharmacy evaluate their current and future didactic and experiential curriculum to help prepare their student pharmacists to be educators for the next generation of student pharmacists, their patients, or interprofessional colleagues; to not evaluate curricula would be a disservice to our learners and ongoing efforts to promote pharmacy education.

Investigation of student pharmacists' perceptions and interest in curricular or cocurricular activities related to academia is warranted. Further separation of IPPE and APPE experiences may reveal additional recommendations such as focusing on specific topics during specific professional years within experiential curriculum. Academic offerings in this area include: development of other types of standardized learning activities or configurations (longitudinal, seminar series, cocurricular, etc) to support academic career preparedness; exposure of student pharmacists to alternative academic roles outside of pharmacy practice; and introduction of a seminar series or cocurricular activities led by student pharmacist organizations. Student pharmacists' exposure to academia as a career option ideally should occur throughout the continuum of their PharmD education.

With the data collected, this subcommittee of the AACP SETF endeavors to create a toolkit for schools and colleges of pharmacy to use in developing academic APPEs, academic electives, and/or longitudinal track topics. This toolkit will also provide suggestions for standardized core learning outcomes and assessments associated with academia career planning and learning experiences, while giving flexibility to also foster further interesting, unique academia-related experiences for some student pharmacists (depending on the timing of opportunities). Ultimately, we hope that this toolkit will provide guidance and support to schools/colleges of pharmacy in developing standardized abilities within academic experiences while providing student pharmacists with an understanding of the different aspects of the profession of academic pharmacy.

\section{CONCLUSION}

Colleges and schools of pharmacy in the United States use various methods to prepare student pharmacists for careers in academia. Standardization in the development of a core curriculum may help facilitate promotion of the academic career path to student pharmacists. The goal of academic pharmacy experiences should be to help student pharmacists define a particular set of abilities required for high-performing future faculty members and to identify those student pharmacists who are potentially a good fit for academic careers. Naturally, this should not replace the more rigorous training that can be achieved through postgraduate residencies and fellowships; instead, this should be complementary to the methods by which residency and fellowship programs prepare residents for academic positions. By exposing student pharmacists to this career path throughout the PharmD curriculum, however, student pharmacists may be more prepared to seek out appropriate postgraduate opportunities that will better refine their skill sets in the areas of teaching, scholarship, and service. Ultimately, these methods may allow schools and colleges of pharmacy to create a sustainable process for cultivating future high-quality faculty members.

\section{ACKNOWLEDGMENTS}

The authors wish to thank Dr. Bonnie Brown, past chair of the AACP Student Engagement Task Force, for her leadership in the beginning of this charge. As well, Susan K. Wright, BS, MHPA, Assessment Analyst, Washington State University College of Pharmacy, for her assistance with Qualtrics and survey implementation.

\section{REFERENCES}

1. American Association of Colleges of Pharmacy. Academic pharmacy's vital statistics for institutions and programs. http://www. aacp.org/about/pages/vitalstats.aspx. Accessed September 8, 2015. 2. Sheaffer EA, Brown BK, Byrd DC, et al. Variables impacting an academic pharmacy career choice. Am J Pharm Educ. 2008;72(3): Article 49.

3. Siracuse MV, Schondelmeyer SW, Hadsall RS, Schommer JC. Assessing career aspirations of pharmacy students. Am J Pharm Educ. 2004;68(3):Article 75.

4. Savage LM, Beall JW, Woolley TW. Factors that influence the career goals of pharmacy students. Am J Pharm Educ. 2009:73(2): Article 28.

5. Baia P, Strang A. An elective course to promote academic pharmacy as a career. Am J Pharm Educ. 2012;76(2):Article 30.

6. Rigelsky J. Exposing doctor of pharmacy students to an academic career through a teaching elective. Am J Pharm Educ. 2008;72(3): Article 72.

7. Sylvia LM. An advanced pharmacy practice experience in academia. Am J Pharm Educ. 2006;70(5):Article 97.

8. Selander LK, Bjornson DC. Description of an elective PharmD teaching clerkship. Am J Pharm Educ. 1995;59(3):273-278.

9. Hammer DP, Paulsen SM. An innovative clerkship in pharmacy education. Am J Pharm Educ. 2001;65(3):284-293.

10. Roche VF, Limpach AL. A collaborative and reflective academic advanced pharmacy practice experience. Am J Pharm Educ. 2011;75 (6):Article 120.

11. Morin AK, Jarvis CI, Pesaturo KA, et al. Descriptive report of a team-taught elective academic-focused advanced pharmacy practice experience. Curr Pharm Teach Learn. 2014;6(2):265-276. 


\section{American Journal of Pharmaceutical Education 2017; 81 (1) Article 6.}

12. Fuentes DG, Ogden RR, Haddad AR, Strang AF. Reframing our pursuit of life balance. Am J Pharm Educ. 2015;79(3):Article 34. 13. Law AV, Bottenberg MM, Brozick AH, et al. A checklist for the development of faculty mentorship programs. Am J Pharm Educ. 2014;78(5):Article 98.

14. Jackevicius CA, Le J, Nazer L, Hess K, Wang J, Law AV. A formal mentorship program for faculty development. Am J Pharm Educ. 2014;78(5):Article 100.

15. Kohn H. A mentoring program to help junior faculty members achieve scholarship success. Am J Pharm Educ. 2014;78(2):Article 29. 16. Metzger AH, Hardy YM, Jarvis C, et al. Essential elements for a pharmacy practice mentoring program. Am J Pharm Educ. 2013;77 (2):Article 23.

17. Guglielmo BJ, Edwards DJ, Franks AS, et al. A critical appraisal of and recommendations for faculty development. Am J Pharm Educ. 2011;75(6):Article 122.

18. American Association of Colleges of Pharmacy. Research grants, fellowships, and scholarship programs. http://www.aacp.org/CAREER/ GRANTS/Pages/default.aspx. Accessed September 9, 2015.

19. Brooks AD. Considering academic pharmacy as a career: opportunities and resources for students, residents, and fellows. Curr Pharm Teach Learn. 2009;1(1):2-9.

20. Sylvia LM. Mentoring prospective pharmacy practice faculty: a seminar series on teaching for pharmacy residents. Am J Pharm Educ. 2004;68(2):Article 38.

21. Romanelli F, Smith KM, Brandt BF. Teaching residents how to teach: a scholarship of teaching and learning certificate program (STLC) for pharmacy residents. Am J Pharm Educ. 2005;69(2): Article 20.

22. Gettig JP, Sheehan AH. Perceived value of a pharmacy resident teaching certificate program. Am J Pharm Educ. 2008;72(5):Article 104. 23. Gonzalvo JD, Ramsey DC, Sheehan AH, Sprunger TL. Redesign of a statewide teaching certificate program for pharmacy residents. Am J Pharm Educ. 2013;77(4):Article 79.

24. Nappi JM. An academician preparation program for pharmacy residents. Am J Pharm Educ. 2013;77(5):Article 101.

25. Greco AJ, Ferreri SP, Persky AM, Marciniak MW.

Characteristics of postgraduate year two pharmacy residency

programs with a secondary emphasis on academia. Am J Pharm Educ. 2013;77(7):Article 143.

26. Wanat MA, Garey KW. A blueprint for transitioning pharmacy residents into successful clinical faculty members in colleges and schools of pharmacy. Am J Pharm Educ. 2013;77(9):Article 200. 27. Wahl KR, Margolis A, Lintner K, Hartkopf K, Martin B. Impact and application of material learned in a pharmacy residency teaching certificate program. Am J Pharm Educ. 2014;78(6):Article 123.
28. Garrison GD, Baia P, Canning JE, Strang AF. An asynchronous learning approach for the instructional component of a dual-campus pharmacy resident teaching program. Am J Pharm Educ. 2015;79(2): Article 29.

29. Kirdahy K, Turner S, Williams J. Description of an academic teaching rotation for postgraduate year 1 pharmacy residents. $\mathrm{Am} J$ Health Syst Pharm. 2012;69(3):228-231.

30. Havrda DE, Engle JP, Anderson KC, et al. Guidelines for resident teaching experiences. Pharmacother. 2013;33(7):e147-e161. 31. Wright EA, Brown B, Gettig J, et al. Teaching and learning curriculum programs: recommendations for post-graduate pharmacy experiences in education. Am J Health Syst Pharm. 2014;71 (15):1292-1302.

32. Dunn BL, Ragucci KR, Garner S, Spencer A. Survey of colleges of pharmacy to assess preparation for and promotion of residency training. Am J Pharm Educ. 2010;74(3):Article 43.

33. Harpe SE. How to analyze Likert and other rating scale data. Curr Pharm Teach Learn. 2015;7(6):836-850.

34. Peeters MJ, Beltyukova SA, Martin BA. Educational testing and validity of conclusions in the scholarship of teaching and learning. Am J Pharm Educ. 2013;77(9):Article 186.

35. Wright EA, Brown B, Gettig J, et al. Teaching and learning curriculum programs: recommendations for postgraduate pharmacy experiences in education. Am J Health Syst Pharm. 2014;71 (15):1292-1302.

36. Surratt CK, Drennen JK, Bricker JD. The "research track" concentration, a new PharmD elective option. Am J Pharm Educ. 2005;69(5):Article 90.

37. New J, Garner S, Ragucci K, Spencer A. An advanced clinical track within a doctor of pharmacy program. Am J Pharm Educ. 2012;76(3): Article 43.

38. Johnson JF, Chesnut RJ, Tice BP. An advanced diabetes care course as a component of a diabetes concentration. Am J Pharm Educ. 2003;67(1):Article 21.

39. Ryan GJ, Foster KT, Unterwagner W, Jia H. Impact of a diabetes certificate program on PharmD students' knowledge and skills. Am J Pharm Educ. 2007;71(5):Article 84.

40. American Association of Colleges of Pharmacy. Vacant budgeted and lost faculty positions - academic year 2013-2014.

AACP Institutional Research Brief, Volume 16. http://www.aacp.org/ resources/research/institutionalresearch/Pages/InstitutionalResearchBriefs. aspx. Accessed October 29, 2015.

41. American Association of Colleges of Pharmacy. Strategic plan 2016-2019. http://www.aacp.org/about/pages/strategicplan.aspx. Accessed October 29, 2015. 